\title{
Formation of Silicon/Carbon Core-Shell Nanowires Using Carbon Nitride Nanorods Template and Gold Catalyst
}

\author{
Ilyani Putri Jamal, Su Kong Chong, Kee Wah Chan, Maisara Othman, \\ Saadah Abdul Rahman, and Zarina Aspanut \\ Low Dimensional Materials Research Center, Department of Physics, Faculty of Science, University of Malaya, \\ 50603 Kuala Lumpur, Malaysia
}

Correspondence should be addressed to Zarina Aspanut; zarinaaspanut@um.edu.my

Received 15 March 2013; Accepted 9 June 2013

Academic Editor: Yanqiu Zhu

Copyright ( 2013 Ilyani Putri Jamal et al. This is an open access article distributed under the Creative Commons Attribution License, which permits unrestricted use, distribution, and reproduction in any medium, provided the original work is properly cited.

\begin{abstract}
In this experiment, silicon/carbon $(\mathrm{Si} / \mathrm{C})$ core-shell nanowires $(\mathrm{NWs})$ were synthesized using gold nanoparticles (Au NPs) coated carbon nitride nanorods (CN NRs) as a template. To begin with, the Au NPs coated CN NRs were prepared by using plasmaenhanced chemical vapor deposition assisted with hot-wire evaporation technique. Fourier transform infrared spectrum confirms the $\mathrm{C}-\mathrm{N}$ bonding of the $\mathrm{CN}$ NRs, while X-ray diffraction pattern indicates the crystalline structure of the Au NPs and amorphous structure of the CN NRs. The Au NPs coated CN NRs were thermally annealed at temperature of $800^{\circ} \mathrm{C}$ in nitrogen ambient for one hour to induce the growth of $\mathrm{Si} / \mathrm{C}$ core-shell NWs. The growth mechanism for the $\mathrm{Si} / \mathrm{C}$ core-shell NWs is related to the nitrogen evolution and solid-liquid-solid growth process which is a result of the thermal annealing. The formation of Si/C core-shell NWs is confirmed by electron spectroscopic imaging analysis.
\end{abstract}

\section{Introduction}

Researches about silicon nanowires ( $\mathrm{Si}$ NWs) have recently attracted much interest because of their novel physical properties that are suitable for many applications such as in solar cells, lithium-ion batteries, thermoelectric devices, and biological sensors [1-4]. However, Si NWs-based devices still encounter several drawbacks such as surface oxidation [57] and rapid volume expansion upon lithium alloying [8, 9], which could significantly reduce their efficiency. In order to avoid this, surface passivation of the NWs by more stable materials are necessary. One of these is carbon (C) which serves as a promising candidate for protective shells due to its high chemical stability and superior physical properties [10]. By comparing the performance of Si NWs with and without $\mathrm{C}$ coating in lithium-ion batteries, Chen et al. [11] observed a higher capacity and better cycle stability when Si NWs with C coating are used as anode materials. On the other hand, Das et al. [12] demonstrated an improvement in the field emission of Si NWs when the NWs are coated with an amorphous $\mathrm{C}$ layer. Several efforts have been carried out to prepare silicon/carbon (Si/C) core-shell NWs [11-13].
Nevertheless, a second carbon coating is usually required after the preparation of Si NWs [11, 12], which can cause contamination of the Si NWs during the sample transfer process.

In this work, we report a synthesis of Si/C core-shell NWs by using carbon nitride nanorods (CN NRs) template coated with gold nanoparticles (Au NPs). The Au NPs and CN NRs coating were prepared separately on an $\mathrm{Si}(111)$ substrate using a hot-wire-assisted plasma-enhanced chemical vapor deposition system. The as-grown Au NPs coated CN NRs sample was then annealed at a temperature of $800^{\circ} \mathrm{C}$ to form the $\mathrm{Si} / \mathrm{C}$ core-shell NWs. $800^{\circ} \mathrm{C}$ is selected as a preferred annealing temperature $\left(T_{a}\right)$ because the nucleation of NWs at the $\mathrm{Au} / \mathrm{Si}$ interface begins at this temperature [14]. The effects of $T_{\mathrm{a}}$ on the structural and morphological changes in the sample were then analyzed.

\section{Experimental}

Au NPs coated CN NRs were deposited on p-type Si(111) substrates using a homebuilt plasma-enhanced chemical 


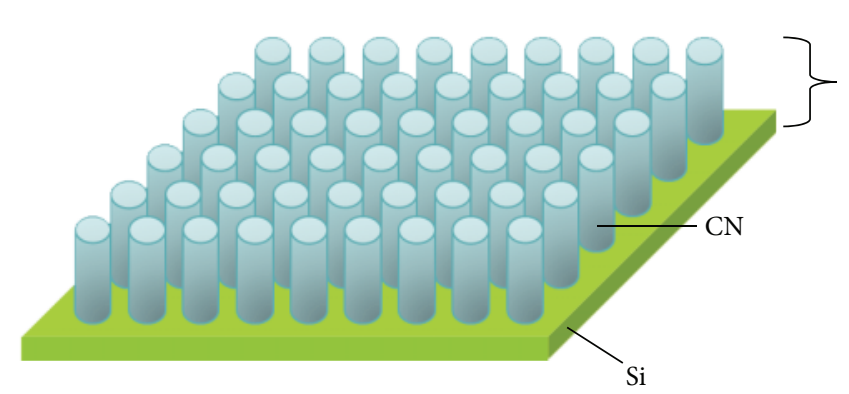

(a)

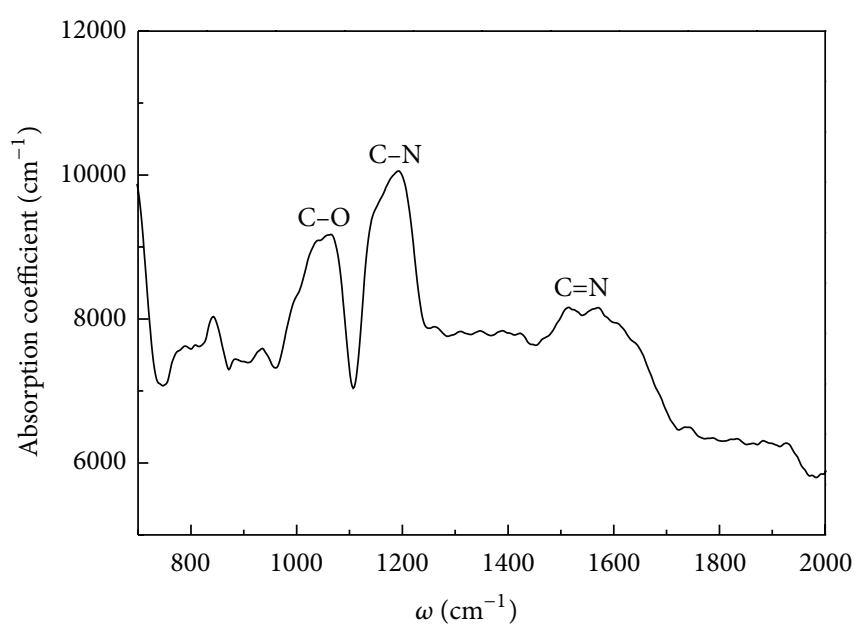

(b)

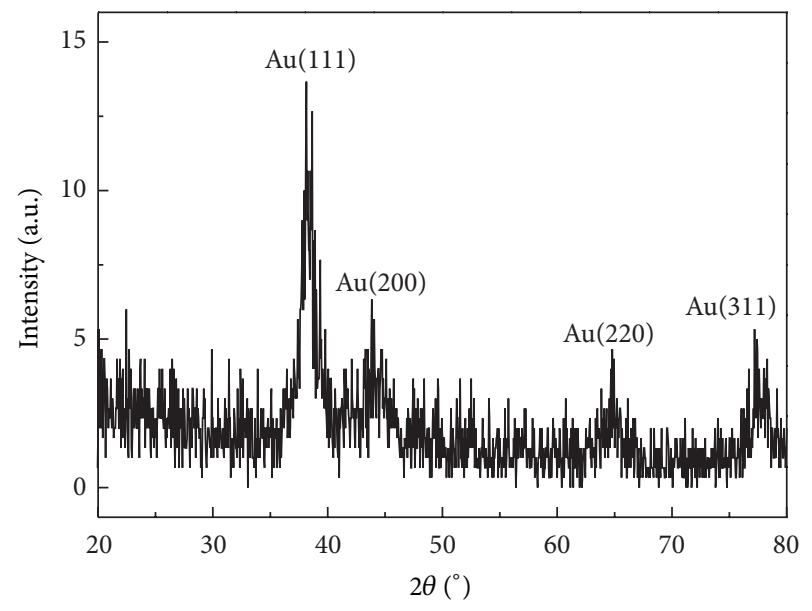

(d)

FIGURE 1: Au NPs coated CN NRs template. Schematic diagram of (a) CN NRs and (c) Au NPs coated CN NRs template. (b) FTIR spectrum of the CN NRs. (d) XRD pattern of the as-grown Au NPs coated CN NRs template.

vapor deposition method assisted with hot-wire evaporation technique. Prior to deposition process, the substrates were chemically cleaned using Radio Corporation of America (RCA) cleaning procedure [15]. The experiment began with a deposition of CN NRs. The radio frequency power, substrate temperature, process pressure, and deposition time were kept at $60 \mathrm{~W}, 100^{\circ} \mathrm{C}, 1.9 \mathrm{mbar}$, and 90 minutes, respectively. At the same time, the flow rate ratio of methane, nitrogen, and hydrogen gases was maintained at 1:4:5 throughout the experiment. Hydrogen treatment was carried out on the substrates for 10 minutes prior to the deposition process in order to remove the contamination on the substrates' surface. After that, an Au wire measuring $4 \mathrm{~mm}$ in length and $1 \mathrm{~mm}$ in diameter was heated by a tungsten filament in vacuum ambient $\left(10^{-3} \mathrm{mbar}\right)$ to form Au NPs on the surface of the deposited CN NRs. The distance from the Au wire to the substrate was fixed at $3 \mathrm{~cm}$. The evaporation process was kept at 10 seconds and was controlled by a shutter assembled below the tungsten filament. The as-prepared Au NPs coated
CN NRs were then thermally annealed in a quartz tube (Carbolyte CFM 12/1 furnace system) at different $T_{\mathrm{a}}$ of 600 and $800^{\circ} \mathrm{C}$ for 1 hour. The annealing process was carried out in nitrogen atmosphere.

The structural properties of the CN NRs were characterized by a Fourier transform infrared (FTIR) spectrometer (Perkin-Elmer System 2000). A Siemens D 5000 $\mathrm{X}$-Ray Diffractometer (XRD) with $\mathrm{Cu}-\mathrm{K} \alpha$ radiation $\left(\lambda_{\alpha}=\right.$ $1.54056 \AA$ ) was used to determine the crystallinity of the $\mathrm{Au}$ NPs and the CN NRs. Field emission scanning electron microscope (FESEM) images and energy dispersive X-ray (EDX) spectra for as-prepared and annealed samples of Au NPs coated CN NRs were obtained by using a Zeiss Auriga FIB-SEM to determine the morphological properties and composition of the nanostructures. As a complementary technique, energy-filtered transmission electron microscopy (EFTEM, Zeiss Libra 120) was employed for electron spectroscopic imaging (ESI) on the samples to obtain specific and improved elemental information of the nanostructures. 

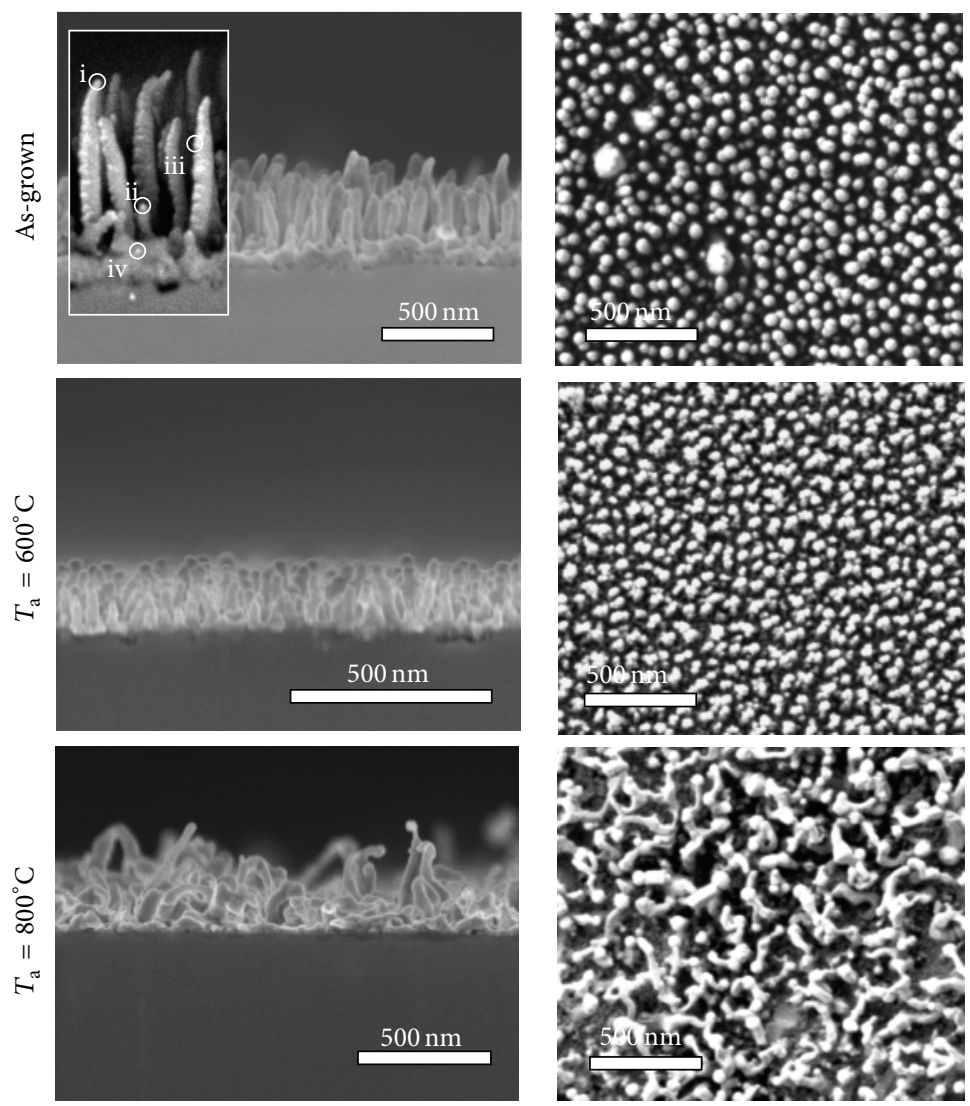

(a)

(b)

FIGURE 2: Morphological analysis of the as-grown and annealed samples. (a) Surface and (b) cross-sectional FESEM images of the as-grown and annealed Au NPs coated CN NRs samples at different $T_{\mathrm{a}}$ of 600 and $800^{\circ} \mathrm{C}$

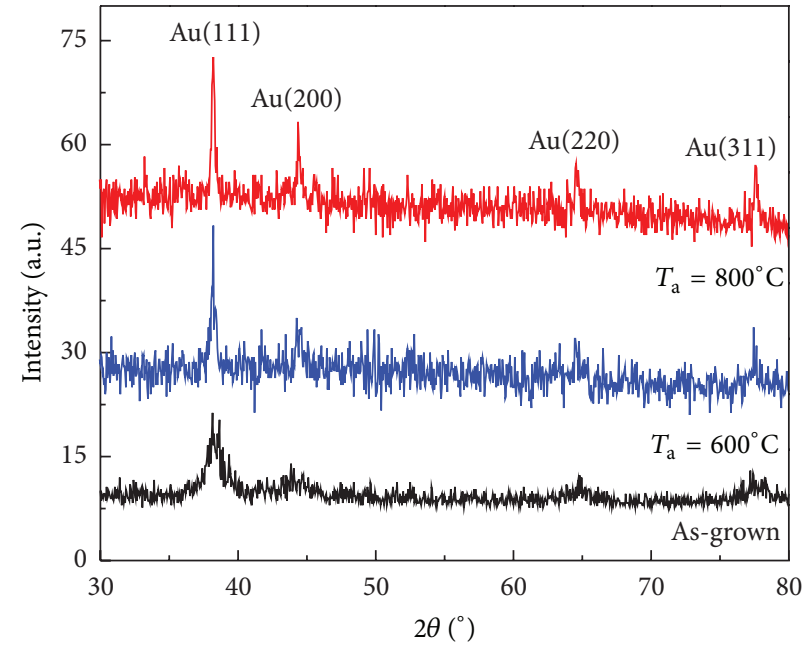

(a)

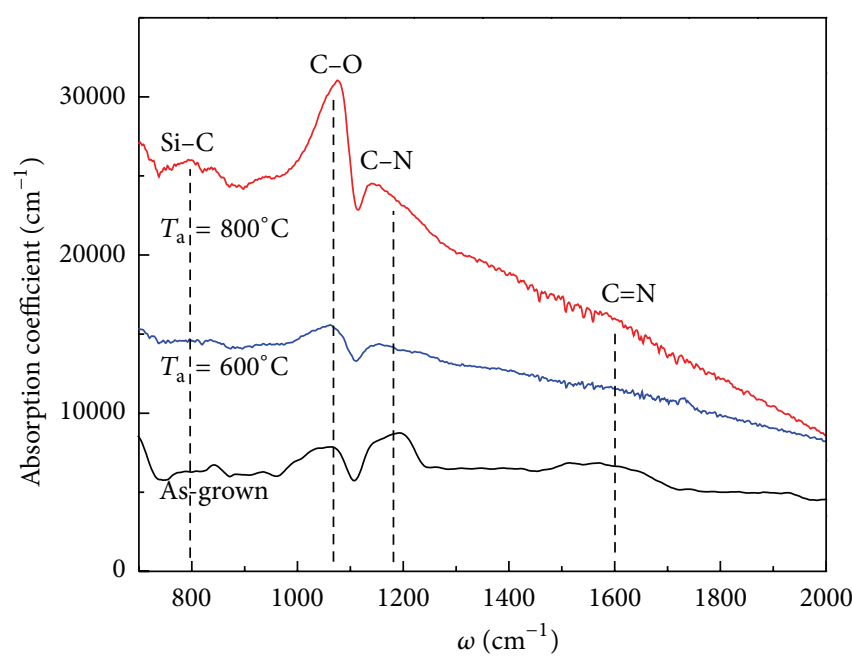

(b)

FIGURE 3: Structural and bonding configuration analyses. (a) XRD pattern and (b) FTIR spectra of the as-grown and annealed Au NPs coated CN NRs sample at different $T_{\mathrm{a}}$. 


\section{Results and Discussion}

Figure 1(a) shows a schematic diagram of CN NRs grown on an $\mathrm{Si}(111)$ substrate. FTIR absorbance spectrum of the CN NRs (Figure 1(b)) revealed three major peaks located at $1080-1160 \mathrm{~cm}^{-1}, 1210-1350 \mathrm{~cm}^{-1}$, and $1500-1800 \mathrm{~cm}^{-1}$. These findings correspond to $\mathrm{C}-\mathrm{O}$ (ketones group) stretching mode [16], $\mathrm{sp}^{3} \mathrm{C}-\mathrm{N}$ [17], and the overlapping of $\mathrm{sp}^{2} \mathrm{C}=\mathrm{N}$ and $\mathrm{C}=\mathrm{C}$ stretching modes [18-20], respectively. This FTIR analysis confirmed the presence of $\mathrm{C}-\mathrm{N}$ bond for the CN NRs. A schematic diagram of $\mathrm{Au}$ NPs deposited on the CN NRs template is shown in Figure 1(c). Figure 1(d) shows the XRD pattern of the Au NPs coated CN NRs. The diffraction peaks are well indexed to the face-centered cubic of $\mathrm{Au}$ crystal (JCP2:00-001-1174). The absence of CN crystalline peaks clearly indicates that the CN NRs are amorphous in structure. Using Scherrer equation, the average Au crystallites size calculated from the $\mathrm{Au}(111)$ crystalline peak [21] was about $10 \pm 1 \mathrm{~nm}$.

Figure 2 shows the FESEM images of as-prepared and annealed $\mathrm{Au}$ NPs coated CN NRs template. The as-prepared sample reveals high density of vertically aligned CN NRs with a diameter and length of $\sim 60$ and $\sim 240 \mathrm{~nm}$, respectively (Figure 2(a) as-grown). Whereas Au NPs with size varying from $40-120 \mathrm{~nm}$ can be seen from the plane view FESEM image (Figure 2(b) as-grown). Backscattered electron image (inset in Figure 2(a) as-grown) further shows that the $\mathrm{Au}$ NPs are freely distributed on the (i) and (ii) tip, (iii) surface, and (iv) interspacing between the CN NRs. Here we observe that the CN NRs tend to slant, forming an inclination angle of $\sim 70-85^{\circ}$ from the substrate, while some of them started to merge with each other, forming bundled structures after annealing at $T_{\mathrm{a}}=600^{\circ} \mathrm{C}$ for 1 hour (Figure $2(\mathrm{a}) 600^{\circ} \mathrm{C}$ ). In addition, the Au NPs on the tip of the CN NRs were found to agglomerate with each other to form Au droplets in larger sizes. This can be seen from plane view FESEM image (Figure 2(b) $600^{\circ} \mathrm{C}$ ) where the Au NPs on the cluster of two or three CN NRs tips combined with each other. However, the rod-like structure is absent at $T_{\mathrm{a}}$ of $800^{\circ} \mathrm{C}$. Worm-like structure of $\mathrm{Si} / \mathrm{C}$ NWs with $\mathrm{Au}$ NPs capping on tip of the NWs is grown throughout the substrate (Figures 2(a) and 2(b) $\left.800^{\circ} \mathrm{C}\right)$. The length of the NWs varies from 100 to $500 \mathrm{~nm}$ with an average diameter of $70 \pm 10 \mathrm{~nm}$.

$\mathrm{XRD}$ and FTIR measurements were carried out on the annealed Au NPs coated CN NRs samples to study the structural and bonding configuration change of the samples upon annealing process. Figure 3(a) shows the XRD patterns of the as-grown and annealed Au NPs coated CN NRs at $T_{\mathrm{a}}$ of 600 and $800^{\circ} \mathrm{C}$. The increase in the intensity and decrease in width of the Au diffraction peaks with $T_{\mathrm{a}}$ indicate an increase in crystallite size of the Au NPs according to Scherrer relation [21]. This is consistent with observation of the Au NPs agglomeration in FESEM analysis. No other diffraction peak is observed in the XRD pattern except that $\mathrm{Au}$ indicates that the NWs formed at $T_{\mathrm{a}} 800^{\circ} \mathrm{C}$ are amorphous in structure. FTIR absorbance spectra of the as-grown and annealed Au NPs coated CN NRs are shown in Figure 3(b). A reduction in the intensity of $\mathrm{C}-\mathrm{N}$ and $\mathrm{C}=\mathrm{N}$ absorption peaks with $T_{\mathrm{a}}$ is observed. This can be attributed to the nitrogen

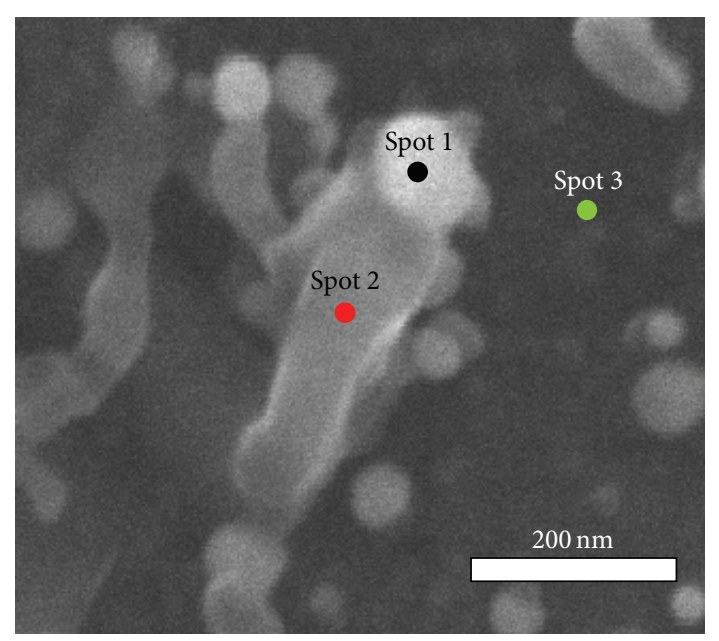

(a)

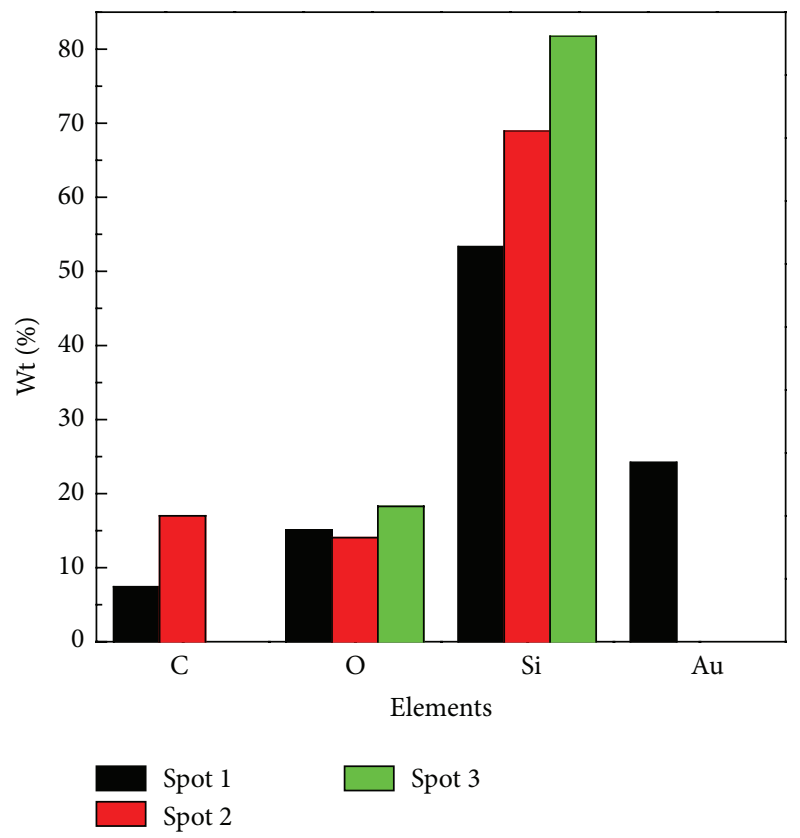

(b)

FIGURE 4: EDX analysis. (a) FESEM image and (b) weight percentage (wt\%) of each element obtained from EDX spectra taken from (Spot 1) catalyst droplet, (Spot 2) NW stem, and (Spot 3) substrate.

evolution from the CN NRs during the annealing process [22]. In addition, an absorption peak located at $\sim 800 \mathrm{~cm}^{-1}$ corresponding to the $\mathrm{Si}-\mathrm{C}$ stretching mode [23] appears in the FTIR spectrum of the Au NPs coated CN NRs annealed at $800^{\circ} \mathrm{C}$. This suggests that the NWs formed at $T_{\mathrm{a}}$ of $800^{\circ} \mathrm{C}$ consist of $\mathrm{Si}$ and $\mathrm{C}$ atoms in the NWs matrix. Meanwhile, the increase in the $\mathrm{C}-\mathrm{O}$ peak intensity with $T_{\mathrm{a}}$ is due to the oxidation of the surface $\mathrm{C}$ atoms during the annealing process $[24,25]$.

EDX analysis was carried out in order to study the composition of the grown NWs at $T_{\mathrm{a}}$ of $800^{\circ} \mathrm{C}$. This was done by obtaining EDX spectra from the catalyst droplet, NW stem, and substrate, which are labeled as Spots 1, 2, 


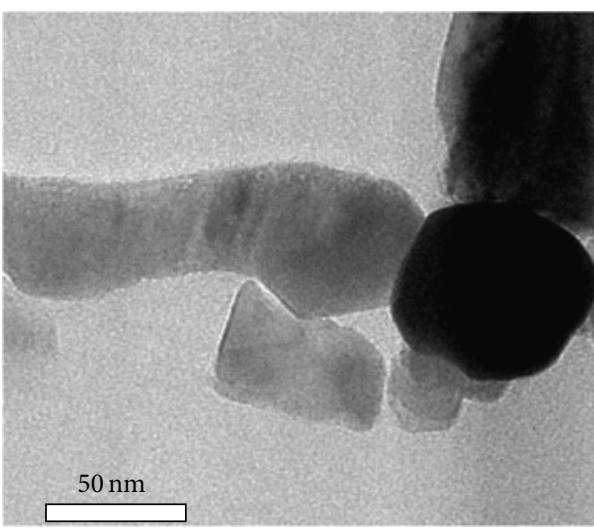

(a)

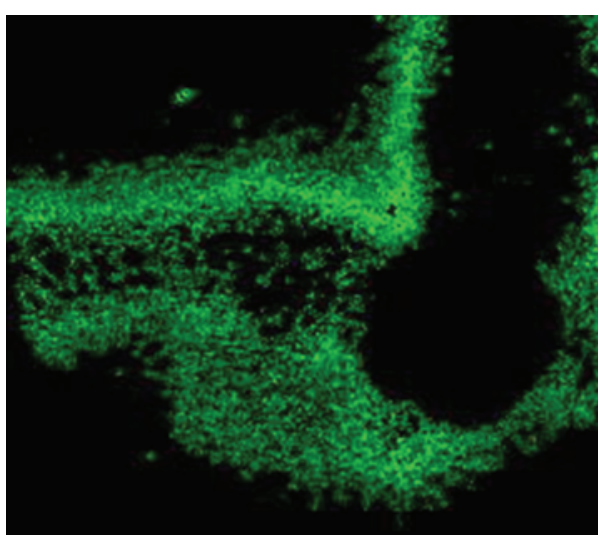

(c)

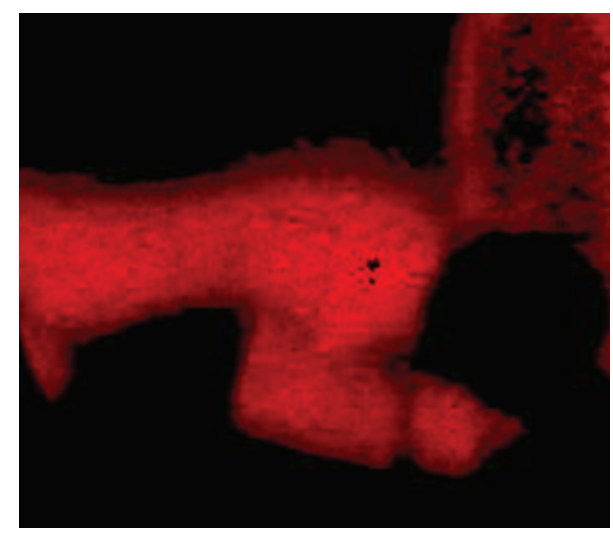

(b)

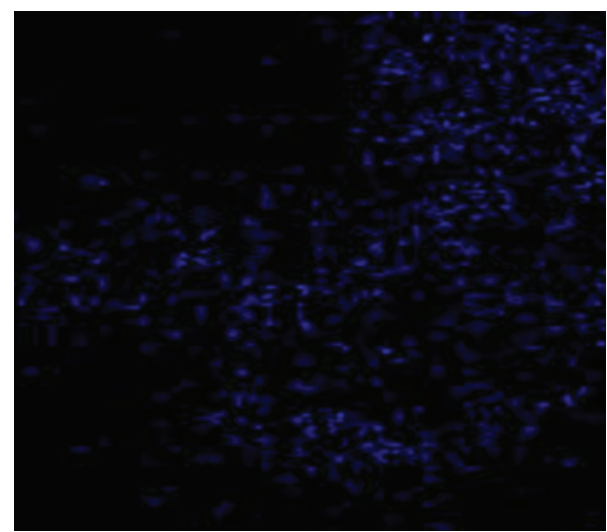

(d)

FIGURE 5: ESI mapping of the Si/C core-shell NWs. (a) TEM image of Si/C core-shell NWs. ESI patterns of the Si/C core-shell NWs in (a) for the elements of (b) Si, (c) C, and (d) N.

and 3, respectively, in Figure 4(a). Figure 4(b) shows the weight percentage (wt\%) of each element detected from the mentioned regions. Generally, high concentration of Si signal was obtained for all spectra due to the high penetration depth $(<1 \mu \mathrm{m})$ of X-ray source [26]. The catalyst droplet (Spot 1) contains high signal of Au and $\mathrm{Si}$ as well as traces of $\mathrm{C}$ and $\mathrm{O}$ elements. This confirms the initial growth of the NWs from the Au NPs. The NW stem (Spot 2) consists of higher Si and C concentration and similar amount of $\mathrm{O}$ element as the catalyst droplet. Meanwhile, only Si and O elements were observed in the substrate side (Spot 3). This indicates that $\mathrm{C}$ and $\mathrm{Si}$ are the main elements within the grown NWs. Similar concentration of $\mathrm{O}$ element ( $\mathrm{wt} \% \sim 14-18 \%$ ) was observed in all scanning regions, indicating a postoxidation of the sample while being exposed to air.

The structure and composition of the Si/C core-shell NWs were further confirmed using an ESI analysis. TEM micrograph of NWs is shown in Figure 5(a). Figures 5(b), 5(c), and 5(d) represent the ESI patterns of $\mathrm{Si}, \mathrm{C}$, and $\mathrm{N}$ elements, respectively, in the NWs. The ESI patterns confirm that the NWs are structurally composed by an Si core and cladded by a C layer. Diameter of the $C$ shell is about $10 \mathrm{~nm}$. Only a small quantity of $\mathrm{N}$ element is detected from ESI pattern which again confirms the $\mathrm{N}$ evolution from $\mathrm{CN}$ NRs via the annealing process.

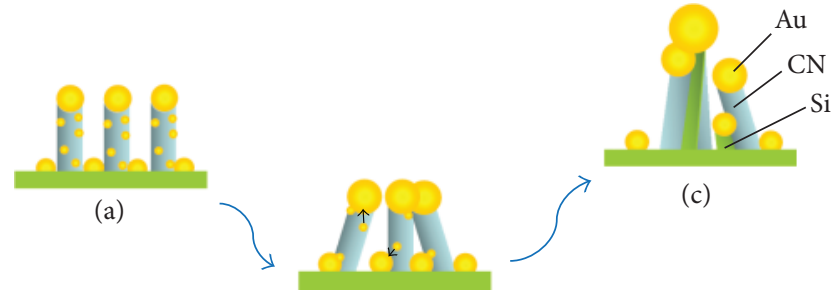

(b)

FIGURE 6: Growth mechanism of the Si/C core-shell NWs. Schematic diagram of (a) as-prepared, (b) annealed at $600^{\circ} \mathrm{C}$ and (c) $800^{\circ} \mathrm{C}$ Au NPs coated CN NRs template. Arrows illustrated in (b) present agglomeration process of Au NPs by joining of smaller sized Au NPs into larger sized Au NPs.

Based on the previous results, we propose a mechanism for phase transformation from $\mathrm{Au}$ NPs coated CN NRs templates into $\mathrm{Si} / \mathrm{C}$ core-shell NWs through the annealing process (Figures 6(a)-6(c)). During the annealing step, the $\mathrm{Au}$ NPs and CN NRs could undergo two processes, namely, Au agglomeration [27] and nitrogen evolution [22], respectively. It has been reported that $[28,29]$ nitrogen atoms can be evolved from the covalent $\mathrm{sp}^{3} \mathrm{C}-\mathrm{N}$ bond upon an $T_{\mathrm{a}}$ of $500^{\circ} \mathrm{C}$ 
onward, leaving small amount of stable graphite-like $\mathrm{sp}^{2} \mathrm{C}=\mathrm{N}$ [30] and mostly graphite-like $\mathrm{sp}^{2} \mathrm{C}=\mathrm{C}$ structures $[31,32]$ at temperature lower than $700^{\circ} \mathrm{C}$. The amorphous $\mathrm{CN}$ films are morphologically more compact after annealing process [33]. This explains the slanting and bundling of the CN NRs at $T_{\mathrm{a}}$ of $600^{\circ} \mathrm{C}$ as a result of a tendency towards more stable graphitic $\mathrm{sp}^{2} \mathrm{C}=\mathrm{C}$ film structure formation (Figure $6(\mathrm{~b})$ ). The agglomeration of $\mathrm{Au}$ NPs usually occurs when annealed $T_{\mathrm{a}}$ is above $500^{\circ} \mathrm{C}[34,35]$, even for those embedding in a dielectric matrix $\left(\mathrm{SiO}_{2}\right.$ or $\left.\mathrm{TiO}_{2}\right)$. It was found that two NWs can join together if their catalysts were combined [36]. This phenomenon could also result in the formation of the $\mathrm{CN}$ NRs bundles. $\mathrm{Au}$ is one of the most effective catalysts for the growth of Si NWs [37]. However, in most cases, Aucatalyzed Si NWs grown from the Si source that originated from $\mathrm{Si}$ substrate can only be achieved at a high temperature of $\sim 1000^{\circ} \mathrm{C}$ [38]. Recently, Márquez et al. [39] demonstrated the growth of Si NWs using Au as catalyst and Si substrate as source via porous anodic alumina mask at a much lower temperature of $800^{\circ} \mathrm{C}$. In this process, the porous anodic alumina mask allows confinement of energy within the nanosized pores, thus lowering the growth temperature. Similarly, in our study, the CN NRs template acts in reducing the growth temperature of Si NWs. Au NPs distributed between the interspace of the CN NRs form eutectic with Si substrate, followed by diffusion of $\mathrm{Si}$ and eventually the precipitation and growth of Si NWs. Additionally, we found that graphite was able to lower the formation temperature of $\mathrm{SiO}_{\mathrm{x}} \mathrm{NWs}$ on Au-coated Si substrate [40]. Hence, the transformation of CN NRs into graphite-like structures also assists the growth of Si NWs. In other words, the Au-induced Si NWs were preferably grown within the bundles of graphite-like NRs as shown in Figure 6(c). The grown Si NWs were then joined with the graphite-like NRs bundles via the combining of $\mathrm{Au}$ NPs, eventually forming Si/C core-shell NWs.

\section{Conclusions}

$\mathrm{Si} / \mathrm{C}$ core-shell NWs were successfully synthesized from $\mathrm{Au}$ NPs coated CN NRs template on Si substrate by using a simple thermal annealing process. The Au NPs acted as a catalyst for the growth of $\mathrm{Si}$ NWs from the Si substrate at a temperature of $800^{\circ} \mathrm{C}$. Annealing process results in $\mathrm{N}$ evolution and transforms the CN NRs into bundled structures. The grown Si NWs combined with the graphitelike $\mathrm{sp}^{2} \mathrm{C}=\mathrm{C}$ bundles form the $\mathrm{Si} / \mathrm{C}$ core-shell NWs. EDX and ESI analyses confirm the $\mathrm{Si} / \mathrm{C}$ core-shell structure of the worm-shaped NWs.

\section{Conflict of Interests}

The authors declare that they have no conflict of interests.

\section{Acknowledgments}

This work was supported by the UM/MOHE High Impact Research Grant Allocation of F000006-21001, the University Malaya Research Grant (UMRG) of RG205-11AFR, the
Exploratory Research Grant Scheme (ERGS) of ER0052012A, and the University of Malaya Postgraduate Research Fund (PPP) of PV071-2012A.

\section{References}

[1] Y. Huang, X. Duan, and C. M. Lieber, "Nanowires for integrated multicolor nanophotonics," Small, vol. 1, no. 1, pp. 142-147, 2005.

[2] J. Xiang, W. Lu, Y. Hu, Y. Wu, H. Yan, and C. M. Lieber, "Ge/Si nanowire heterostructures as high-performance fieldeffect transistors," Nature, vol. 441, no. 7092, pp. 489-493, 2006.

[3] P. R. Bandaru and P. Pichanusakorn, "An outline of the synthesis and properties of silicon nanowires," Semiconductor Science and Technology, vol. 25, no. 2, Article ID 024003, 2010.

[4] M. Shao, D. D. D. Ma, and S.-T. Lee, "Silicon nanowiresSynthesis, properties, and applications," European Journal of Inorganic Chemistry, no. 27, pp. 4264-4278, 2010.

[5] M. Ohring, Reliability and Failure of Electronic Materials and Devices, Academic Press, New York, NY, USA, 1998.

[6] A. R. Guichard, D. N. Barsic, S. Sharma, T. I. Kamins, and M. L. Brongersma, "Tunable light emission from quantum-confined excitons in $\mathrm{TiSi}_{2}$-catalyzed silicon nanowires," Nano Letters, vol. 6, no. 9, pp. 2140-2144, 2006.

[7] H. I. Liu, D. K. Biegelsen, F. A. Ponce, N. M. Johnson, and R. F. W. Pease, "Self-limiting oxidation for fabricating sub-5 nm silicon nanowires," Applied Physics Letters, vol. 64, no. 11, pp. 1383-1385, 1994.

[8] U. Kasavajjula, C. Wang, and A. J. Appleby, "Nano- and bulksilicon-based insertion anodes for lithium-ion secondary cells," Journal of Power Sources, vol. 163, no. 2, pp. 1003-1039, 2007.

[9] B. A. Boukamp, G. C. Lesh, and R. A. Huggins, "All-solid lithium electrodes with mixed-conductor matrix," Journal of the Electrochemical Society, vol. 128, no. 4, pp. 725-729, 1981.

[10] A.-H. Lu, W.-C. Li, N. Matoussevitch, B. Spliethoff, H. Bönnemann, and F. Schüth, "Highly stable carbon-protected cobalt nanoparticles and graphite shells," Chemical Communications, no. 1, pp. 98-100, 2005.

[11] H. Chen, Z. Dong, Y. Fu, and Y. Yang, "Silicon nanowires with and without carbon coating as anode materials for lithium-ion batteries," Journal of Solid State Electrochemistry, vol. 14, no. 10, pp. 1829-1834, 2010.

[12] N. S. Das, D. Banerjee, and K. K. Chattopadhyay, "Enhancement of electron field emission by carbon coating on vertically aligned Si nanowires," Applied Surface Science, vol. 257, no. 22, pp. 9649-9653, 2011.

[13] H. Kim and J. Cho, "Superior lithium electroactive mesoporous Si@carbon core-shell nanowires for lithium battery anode material," Nano Letters, vol. 8, no. 11, pp. 3688-3691, 2008.

[14] L. Ren, H. Li, and L. Ma, The Selective Growth of Silicon Nanowires and Their Optical Activation, InTech, 2011.

[15] M.-H. Cho, "Structural and electrical characteristics of $\mathrm{Y}_{2} \mathrm{O}_{3}$ films grown on oxidized $\mathrm{Si}(100)$ surface," Journal of Vacuum Science and Technology A, vol. 19, no. 1, pp. 192-199, 2001.

[16] Z.-M. Ren, P.-N. Wang, Y.-C. Du, Z.-F. Ying, and E.-M. Li, "Optical studies on the deposition of carbon nitride films by laser ablation," Applied Physics A, vol. 65, no. 4-5, pp. 407-409, 1997.

[17] Y. K. Yap, S. Kida, T. Aoyama, Y. Mori, and T. Sasaki, "Influence of negative dc bias voltage on structural transformation of carbon nitride at $600^{\circ} \mathrm{C}$," Applied Physics Letters, vol. 73, no. 7, pp. 915-917, 1998. 
[18] W. Kulisch, M. P. Delplancke-Ogletree, J. Buliř et al., "Characterization of magnetron sputtered carbon nitride films," Diamond and Related Materials, vol. 8, no. 6, pp. 1039-1045, 1999.

[19] J. Zemek, M. Jelínek, V. Vorlíček, M. Trchová, and J. Lančok, "Carbon nitride layers created by laser deposition combined with RF discharge," Diamond and Related Materials, vol. 9, no. 3, pp. 548-551, 2000.

[20] M. Othman, R. Ritikos, N. H. Khanis et al., "Effects of rf power on the structural properties of carbon nitride thin films prepared by plasma enhanced chemical vapour deposition," Thin Solid Films, vol. 519, no. 15, pp. 4981-4986, 2011.

[21] S. K. Chong, B. T. Goh, Z. Aspanut et al., "Silicon nanostructures fabricated by $\mathrm{Au}$ and $\mathrm{SiH}_{4}$ co-deposition technique using hotwire chemical vapor deposition," Thin Solid Films, vol. 520, no. 1, pp. 74-78, 2011.

[22] Z. H. Huang, B. Yang, C. S. Liu, L. P. Guo, X. J. Fan, and D. J. Fu, "Effect of annealing on the composition, structure and mechanical properties of carbon nitride films deposited by middle-frequency magnetron sputtering," Materials Letters, vol. 61, no. 16, pp. 3443-3445, 2007.

[23] D. Song, E.-C. Cho, Y.-H. Cho et al., "Evolution of Si (and SiC) nanocrystal precipitation in SiC matrix," Thin Solid Films, vol. 516, no. 12, pp. 3824-3830, 2008.

[24] X.-W. Du, Y. Fu, J. Sun, P. Yao, and L. Cui, "Intensive light emission from SiCN films by reactive RF magnetron sputtering," Materials Chemistry and Physics, vol. 103, no. 2-3, pp. 456-460, 2007.

[25] K. Chan, B. T. Goh, S. A. Rahman, M. R. Muhamad, C. F. Dee, and Z. Aspanut, "Annealing effect on the structural and optical properties of embedded $\mathrm{Au}$ nanoparticles in silicon suboxide films," Vacuum, vol. 86, no. 9, pp. 1367-1372, 2012.

[26] S. K. Chong, B. T. Goh, Y.-Y. Wong et al., "Structural and photoluminescence investigation on the hot-wire assisted plasma enhanced chemical vapor deposition growth silicon nanowires," Journal of Luminescence, vol. 132, no. 6, pp. 1345-1352, 2012.

[27] K. Chan, Z. Aspanut, B. Goh et al., "Effects of post-thermal annealing temperature on the optical and structural properties of gold particles on silicon suboxide films," Applied Surface Science, vol. 257, no. 6, pp. 2208-2213, 2011.

[28] Z. Zhou, L. Xia, and M. Sun, "The investigation of carbon nitride films annealed at different temperatures," Applied Surface Science, vol. 210, no. 3-4, pp. 293-300, 2003.

[29] G. L. Ghen, Y. Li, J. Lin, C. H. A. Huan, and Y. P. Guo, "Effect of thermal annealing on reactive radio-frequency magnetronsputtered carbon nitride films," Journal of Physics D, vol. 32, no. 3, pp. 195-199, 1999.

[30] X. C. Wang, Z. Q. Li, P. Wu, E. Y. Jiang, and H. L. Bai, "Annealing effects on the microstructure of amorphous carbon nitride films," Applied Surface Science, vol. 253, no. 4, pp. 2087-2092, 2006.

[31] I. Jiménez, R. Gago, J. M. Albella, and L. J. Terminello, "Xray absorption studies of bonding environments in graphitic carbon nitride," Diamond and Related Materials, vol. 10, no. 3-7, pp. 1170-1174, 2001.

[32] J. J. Li, W. T. Zheng, H. H. Wu et al., "Compositional and structural modifications of amorphous carbon nitride films induced by thermal annealing," Journal of Physics D, vol. 36, no. 16, pp. 2001-2005, 2003.

[33] L. Jiang, A. G. Fitzgerald, and M. J. Rose, "The effect of postdeposition annealing on chemical bonding in amorphous carbon nitride films prepared by dc magnetron sputtering," Applied Surface Science, vol. 181, no. 3-4, pp. 331-338, 2001.
[34] J.-Y. Kwon, T.-S. Yoon, K.-B. Kim, and S.-H. Min, “Comparison of the agglomeration behavior of $\mathrm{Au}$ and $\mathrm{Cu}$ films sputter deposited on silicon dioxide," Journal of Applied Physics, vol. 93, no. 6, pp. 3270-3278, 2003.

[35] S. Lee, C. Fan, T. Wu, and S. L. Anderson, "Agglomeration, support effects, and $\mathrm{CO}$ adsorption on $\mathrm{Au} / \mathrm{TiO}_{2}\left(\begin{array}{lll}1 & 1 & 0\end{array}\right)$ prepared by ion beam deposition," Surface Science, vol. 578, no. 1-3, pp. 5-19, 2005.

[36] S. Huang, Y. Wu, X. Zhu et al., "VLS growth of $\mathrm{SiO}_{x}$ nanowires with a stepwise nonuniformity in diameter," Journal of Applied Physics, vol. 109, no. 8, Article ID 084328, 2011.

[37] M. Shao, D. D. D. Ma, and S.-T. Lee, "Silicon nanowiressynthesis, properties, and applications," European Journal of Inorganic Chemistry, no. 27, pp. 4264-4278, 2010.

[38] I. K. Ng, K. Y. Kok, S. S. Zainal Abidin et al., "Gold catalysed growth of silicon nanowires and core-shell heterostructures via solid-liquid-solid process and galvanic displacement," Materials Research Innovations, vol. 15, no. 2, pp. S55-S58, 2011.

[39] F. Márquez, C. Morant, V. López, F. Zamora, T. Campo, and E. Elizalde, "An alternative route for the synthesis of silicon nanowires via porous anodic alumina masks," Nanoscale Research Letters, vol. 6, article 495, pp. 1-7, 2011.

[40] S.-H. Li, X.-F. Zhu, and Y.-P. Zhao, "Carbon-assisted growth of $\mathrm{SiO}_{x}$ nanowires," Journal of Physical Chemistry B, vol. 108, no. 44, pp. 17032-17041, 2004. 

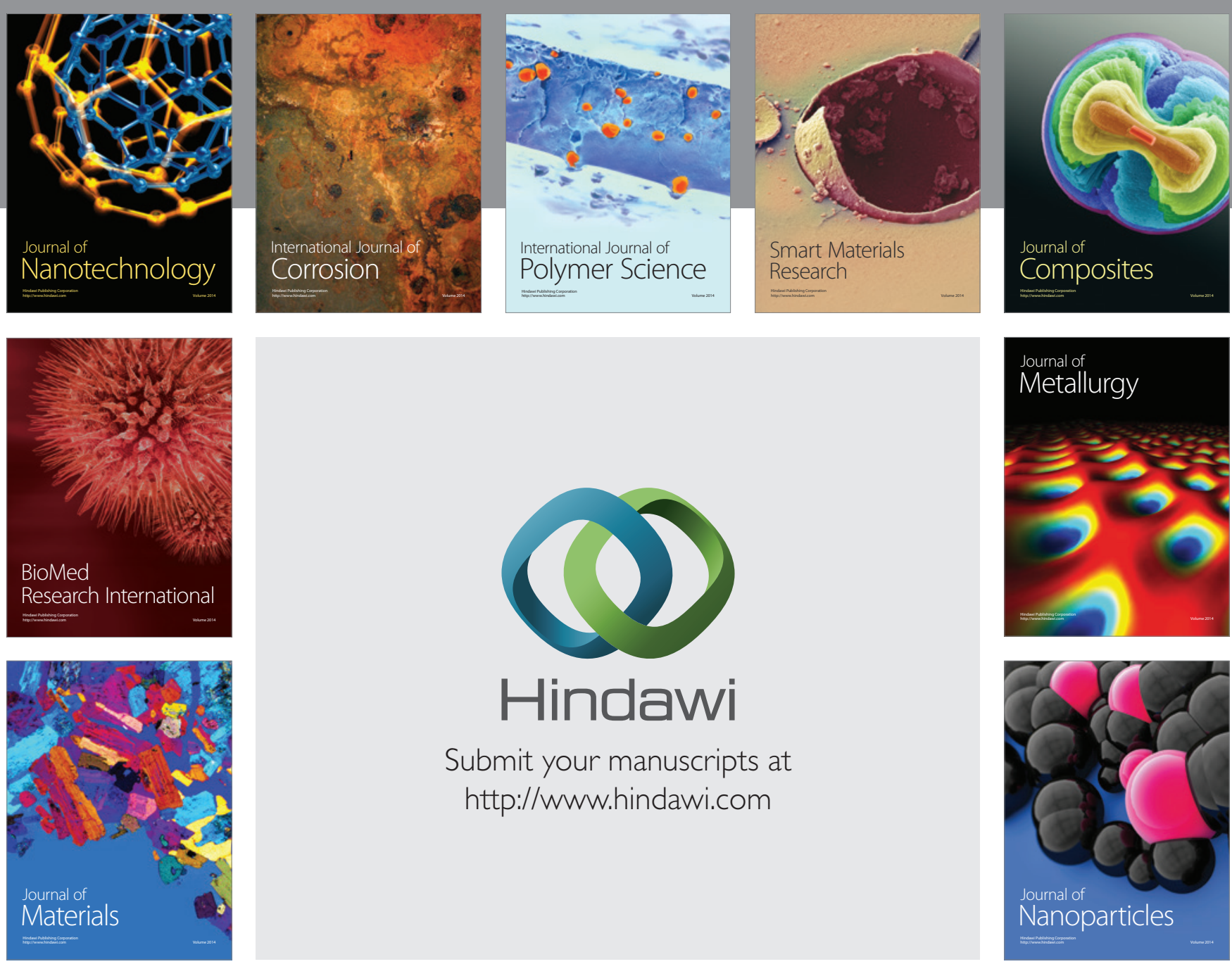

Submit your manuscripts at http://www.hindawi.com
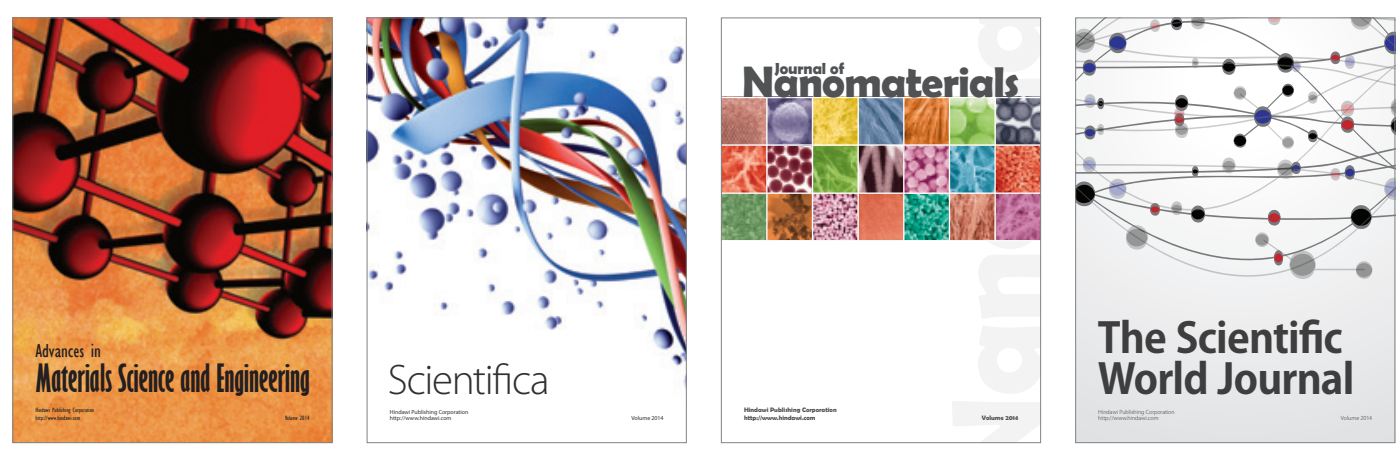

\section{The Scientific World Journal}
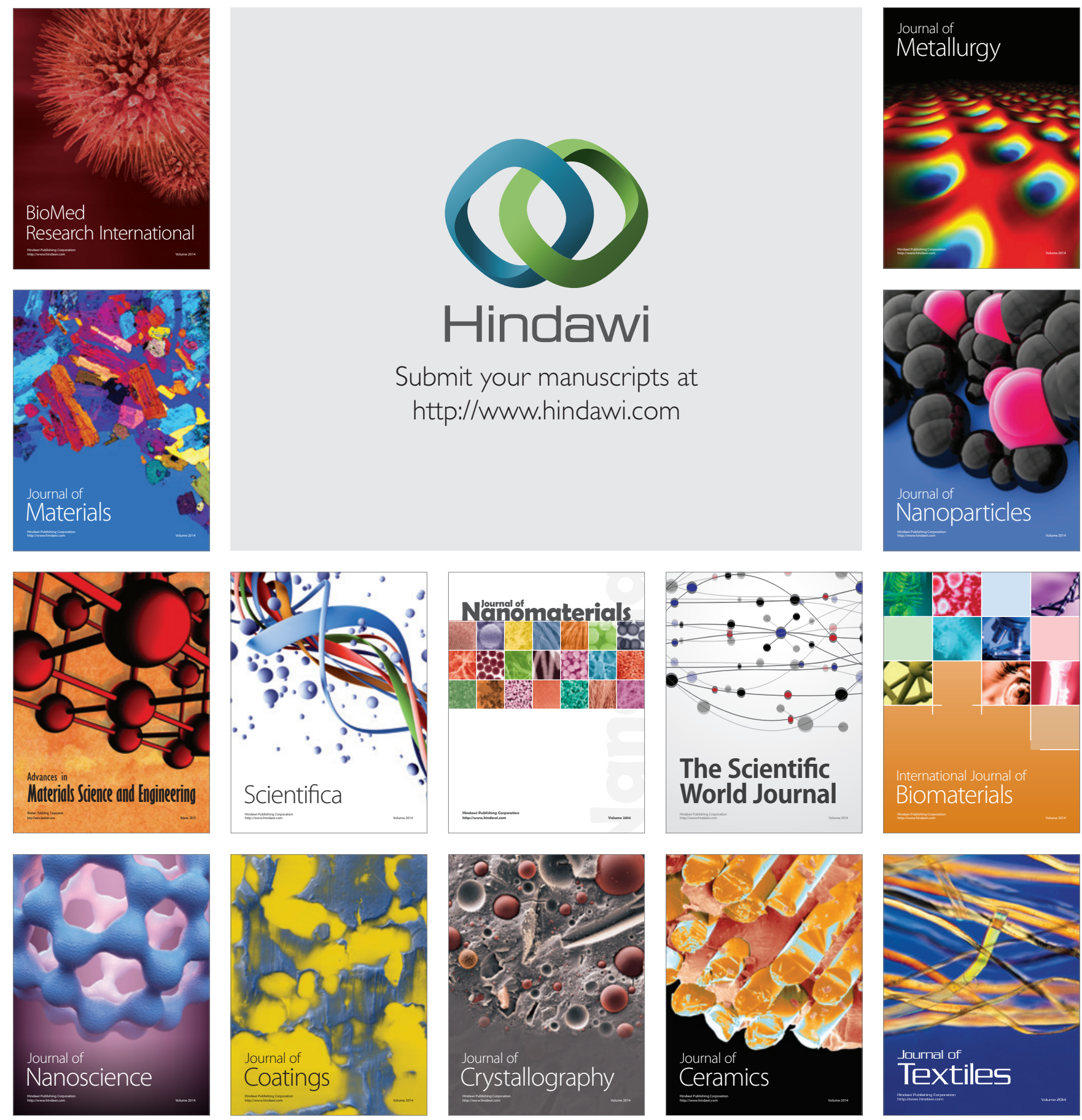